\title{
Processo de trabalho: avaliação dos enfermeiros de um hospital de ensino
}

\author{
Working process: evaluation of the Nursing staff of a teaching \\ hospital
}

\section{Proceso de trabajo: evaluación de Enfermería de un hospital de enseñanza}

Maira Buss Thofehrn¹, Leandro Rauber Joner², Adrize Rutz Porto ${ }^{3}$, Manuela Gomes Campos Borel4, Michelle Barboza Jacondino ${ }^{5}$, Neyla Cristina Carvalló Viana 6

1 Programa de Pós-graduação em Enfermagem da Universidade Federal de Juiz de Fora/MG. E-mail: mairabusst@hotmail.com.

2 Prefeitura Municipal de Osório/RS. E-mail: canigia.joner@hotmail.com.

3 Universidade Federal de Pelotas, Pelotas/RS. E-mail: adrizeporto@gmail.com.

4 Universidade Federal de Juiz de Fora/MG. Juiz de Fora/MG. Endereço: Rua José Lourenço Kelmer, s/n-Campus Universitário, Bairro: São Pedro, Cep 36036-900, Juiz de Fora/MG. E-mail: manu.ufjf@yahoo.com.

5 Hospital Escola da Universidade Federal de Pelotas/RS. E-mail: michellejacondino@gmail.com.

6 Universidade Federal de Pelotas, Pelotas/RS. E-mail: neylacarvallo@gmail.com . 
Informações do Artigo: Recebido em: 01/07/2019 Aceito em: 17/10/2019
DOI: 10.34019/2446-5739.2019.v5.27175

\section{RESUMO}

Objetivo: conhecer o processo de trabalho dos enfermeiros de um hospital de ensino, e sua relação com a assistência de Enfermagem. Metodologia: pesquisa qualitativa, exploratória, descritiva. Como participantes, contou-se com a presença de nove enfermeiros de um hospital de ensino de médio porte. Os dados foram coletados no segundo semestre de 2012 por meio de dois encontros de grupo focal e analisados pela proposta operativa de Minayo. Resultados: revelam-se três categorias temáticas: visão dos enfermeiros acerca das fragilidades no processo de trabalho da Enfermagem, visão dos enfermeiros acerca das potencialidades no processo de trabalho da Enfermagem e visão dos enfermeiros acerca das estratégias para mudança no processo de trabalho da Enfermagem. Considerações finais: esta pesquisa emergiu a necessidade de construir momentos que permitam a reunião dos profissionais em espaços de discussão e troca de informações, de maneira que os participantes discutam o seu processo de trabalho, e não somente recebam ordens.

\section{Descritores:}

Enfermagem; Cuidados de enfermagem; Organização e administração.

\section{ABSTRACT}

Objective: to know the nursing work process of a teaching hospital, and its relationship with nursing care. Methodology: qualitative, exploratory, descriptive research. Participants included nine nurses from a medium-sized teaching hospital. Data were collected in the second half of 2012 through two focus group meetings and analyzed by Minayo's operational proposal. Results: three thematic categories are revealed: nurses' view of weaknesses in the nursing work process, nurses' view of the potentialities in the nursing work process, nurses' vision about strategies for change in the nursing work process. Final considerations: this research revealed the need to build moments that allow professionals to gather in discussion and information exchange spaces, so that the participants discuss their work process, and not only receive orders.

Descriptors:

Nursing; Nursing care; Organization and administration.

\section{RESUMEN}

Objetivo: conocer el proceso de trabajo de los enfermeros de un hospital de enseñanza, y su relación con la asistencia de enfermería. Metodología: investigación cualitativa, exploratória, descriptiva. Como participantes se contó con la presencia de nueve enfermeros de un hospital de enseñanza de mediano porte. Los datos fueron recolectados en el segundo semestre de 2012 por medio de dos encuentros de grupo focal y analizados por la propuesta operativa de Minayo. Resultados: se revela tres categorías temáticas: visión de los enfermeros acerca de las fragilidades en el proceso de trabajo de la enfermería, visión de los enfermeros acerca de las potencialidades en el proceso de trabajo de la enfermería, visión de los enfermeros acerca de las estrategias para el cambio en el proceso de trabajo de la enfermería. Consideraciones finales: em esta investigación surgió la necesidad de construir momentos que permitan la reunión de los profesionales en espacios de discusión e intercambio de informaciones, de manera que los participantes discutan su proceso de trabajo, y no sólo reciban órdenes.

Descriptores:

Enfermería; Atención de enfermería; Organización y administración.

\section{INTRODUÇÃO}

A Enfermagem, exercida no contexto do trabalho coletivo em saúde, é uma profissão que tem papel fundamental na assistência. Consiste em uma prática social com certo nível de complexidade, a qual Ihe é atribuída certa valoração para a vida humana. Além disso, podem apresentar dimensões básicas voltadas para as práticas do âmbito da prestação de cuidados individuais, familiares e grupos 
sociais, bem como nas dimensões de cuidar, pesquisar, administrar, gerenciar e participar politicamente ${ }^{(1-3)}$.

Nessa perspectiva, a Enfermagem tem como objeto de trabalho o ser humano, a família ou as comunidades que necessitam de cuidados de saúde. Para investir no objeto, conta com uma força de trabalho, a equipe de Enfermagem, composta por auxiliares de Enfermagem, técnicos de Enfermagem e enfermeiros(4). Tal equipe trabalha em conjunto em prol de um objetivo em comum: prestar uma assistência de Enfermagem com qualidade, cuidando do indivíduo fragilizado ou doente, a fim de promover sua saúde e atender às suas necessidades. Como tarefa profissional do enfermeiro, há o cuidado terapêutico, compreendida como uma interação entre o profissional de Enfermagem e 0 ser humano que necessita de um cuidado específico.

Cabe destacar que tal relação é sustentada na competência técnica e legal, no autocuidado do profissional, quanto ao compromisso ético e estético da equipe de Enfermagem ao desenvolvêlo(5).Para que a equipe consiga alcançar esse cuidado terapêutico, utilizam-se de ferramentas ou instrumentos de trabalho, que consistem em (a) científico: construção do saber e teorias de Enfermagem; (b) metodológico: modelos de assistência em Enfermagem; sistematização da assistência de Enfermagem (c) cuidado: procedimentos e técnicas de Enfermagem; (d) educacionais: educação para saúde; e (d) gerenciais: organização de ambiente, materiais e relações humanas. ${ }^{(5)}$

Quando a equipe de Enfermagem desenvolve todo o processo citado, origina-se um produto de trabalho, que consiste em um ser humano transformado pelo cuidado terapêutico(6).

Não obstante, o conhecimento acerca dos elementos que cercam o processo de trabalho torna-se importante para o profissional ser sensibilizado com a consciência de que, ao realizá-lo de maneira efetiva, pode aprimorar o cuidado no trabalho. Nesse sentido, é relevante destacar que a construção de um ambiente de trabalho saudável pela equipe e com qualidade na assistência pode advir, em parte, do conhecimento a respeito do trabalho desenvolvido no local, além do envolvimento afetivo da equipe em torno de um mesmo objetivo(7).

Quando o foco é a área da saúde, o desempenho dos indivíduos no trabalho está relacionado diretamente com a saúde da população, o que acarreta mais cobrança e responsabilidade sobre 0 cuidado do ser humano prestado por essa categoria de trabalhadores. É por esse motivo que se busca compreender o processo de trabalho dos enfermeiros, para se avaliar e promover reflexões que possibilitem a transformação da visão dos indivíduos a respeito do exercício profissional de cada um.

Sensibilizar os enfermeiros é imprescindível. Esses trabalhadores são os agentes multiplicadores e líderes da equipe de Enfermagem. Assim, podem induzir todos à reflexão, de modo a esclarecer e direcionar o objeto de trabalho na Enfermagem, ou seja, o usuário. $O$ estudo, portanto, 
teve como objetivo avaliar procedimentos junto aos enfermeiros de um hospital de ensino, quanto às facilidades, às dificuldades e à construção de estratégias para facilitar a organização do trabalho.

\section{MÉTODOS}

\section{Tipo de estudo e procedimentos metodológicos}

Pesquisa de natureza qualitativa, exploratória e descritiva, a qual fez parte de um projeto guarda-chuva intitulado "Avaliação participativa do processo de trabalho da equipe de Enfermagem do Hospital Escola de Pelotas, Rio Grande do Sul".

\section{Cenário do estudo}

O cenário do estudo é um Hospital-escola de médio porte localizado em Pelotas, cidade do interior do estado de Rio Grande do Sul, no Brasil.

\section{Fonte de dados}

A fonte dos dados deu-se através de dois grupos focais cujos participantes são enfermeiros atuantes nas unidades abertas de internação do hospital de ensino.

\section{Coleta e organização dos dados}

Como coleta de dados, utilizou-se a técnica de grupo focal, a qual se entende como modo de coletar dados a partir das experiências, discussões e percepções em grupo, no qual o interesse não está na busca de informações individuais, e, sim, no resultado obtido a partir de um amplo debate no grupo(8). A coleta de dados ocorreu no segundo semestre de 2012, por meio de dois encontros de grupo focal, os quais foram gravados. Para conduzir os encontros, utilizaram-se os resultados da coleta de dados do projeto "guarda-chuva" que foi o disparador para a discussão do grupo focal. Além disso, os participantes foram contatados mediante a inserção do pesquisador no cenário do estudo, sendo todos os enfermeiros das unidades abertas de internação convidados a participar dos grupos. Para os dois encontros, utilizou-se a seguinte questão norteadora: qual a opinião dos enfermeiros sobre a avaliação de seu processo de trabalho, tendo como base os dados obtidos no projeto guarda-chuva?

\section{Etapas do trabalho}

No primeiro encontro, estavam presentes nove enfermeiros, os quais inicialmente se apresentaram. Posteriormente, foi feita apresentação do projeto, bem como dos resultados já coletados 
no projeto guarda-chuva. Na sequência, abriu-se a discussão. A reunião teve a duração de uma hora e trinta minutos, e os participantes expressaram a vontade de novos encontros para ainda serem discutidas as potencialidades e fragilidades do processo de trabalho dos enfermeiros e a possibilidade de debater mudanças a respeito do tema.

No segundo momento, este com duração de uma hora, brevemente se relembrou o encontro anterior. Em seguida, logo foi aberta a discussão dos dados obtidos, além de possíveis estratégias a serem implementadas no contexto dos indivíduos inseridos. O segundo encontro também contou com a participação de nove participantes.

Cabe salientar que, nos grupos focais, manteve-se o moderador, que guiou e conduziu a conversação com vistas a promover uma discussão produtiva e um observador, a fim de auxiliar e influenciar a discussão. Assim, o observador foi um pesquisador e membro do grupo de pesquisa Núcleo de Estudos em Práticas de Saúde em Enfermagem (NEPEn) da Universidade Federal de Pelotas (RS), com experiência na técnica de coleta de dados de grupo focal.

\section{Análise dos dados}

As informações foram coletas, transcritas, validadas junto aos participantes e analisadas pela proposta operativa de análise de temática de Minayo(9), o que resultou em três categorias temáticas: visão dos enfermeiros acerca das fragilidades no processo de trabalho da Enfermagem, visão dos enfermeiros acerca das potencialidades no processo de trabalho da Enfermagem e visão dos enfermeiros acerca das estratégias para a mudança no processo de trabalho da Enfermagem.

\section{Aspectos éticos}

Os preceitos éticos foram mantidos de acordo com o Código de Ética dos Profissionais de Enfermagem, além de atender às recomendações da Resolução no 466/2012 do Ministério da Saúde ${ }^{(10)}$. A pesquisa foi aprovada pelo Comitê de Ética em Pesquisa da Faculdade de Enfermagem da Universidade Federal de Pelotas (RS), sob o protocolo № 003/2011. Para assegurar o anonimato dos participantes, atribuíram-se códigos alfanuméricos em que a sequência foi definida pela ordem de realização das entrevistas: iniciando com P1 e terminando com P9.

\section{RESULTADOS}

Revelaram-se nesta pesquisa três categorias temáticas: visão dos enfermeiros acerca das fragilidades no processo de trabalho da Enfermagem, visão dos enfermeiros acerca das potencialidades no processo de trabalho da Enfermagem e visão dos enfermeiros acerca das 
estratégias para a mudança no processo de trabalho da Enfermagem, a partir das quais serão apresentados e discutidos os resultados posteriormente.

\section{Visão dos enfermeiros acerca das fragilidades no processo de trabalho da Enfermagem}

A dificuldade dos enfermeiros em exercer a liderança junto à equipe de Enfermagem foi uma fragilidade significativa identificada na pesquisa.

[...] o líder tem a necessidade de ver o que precisa. A equipe também vai seguir ele. Acho que as pessoas têm dificuldade mesmo. $O$ enfermeiro tem dificuldade de ampliar o olhar do enfermeiro [...]. Existe uma lacuna de deficiência do profissional enfermeiro, uma dificuldade enorme de exercer o poder de mando e mandar (P2).

Outro aspecto percebido nas falas foi a ausência de normas e rotinas inseridas no processo de trabalho.

A gente tem dificuldade com processos de trabalho, com certeza [...].As normas e rotinas... Há dificuldade também de colocar em prática. Tudo o que é mudança é uma dificuldade (P2).

Uma das coisas que foram ditas nas fragilidades, a questão de normas e rotinas, realmente eu acho que está faltando. A gente está atualizando normas e rotinas. Tem setores que já estão mais adiantados outros menos (P7).

Do mesmo modo, outra fragilidade identificada foi a falta de implementação da Sistematização da Assistência de Enfermagem (SAE) no hospital.

[...] realmente o enfermeiro da assistência faz, mas não coloca no papel. Ele acha que aquilo [...] não é importante, que não vai dar tempo, que vai ser mais uma atividade, mais uma tarefa [...]. Tu é capaz. Aquilo tu já realiza no teu dia a dia. É só uma forma mais sistematizada de tu realizar seu trabalho, e que muitas vezes já vai facilitar para o colega que vem (P5).

No processo de trabalho dos enfermeiros, a dicotomia existente entre os vínculos profissionais celetista e estatutário também é elemento frágil que prejudica o andamento do trabalho.

A diferença entre FAU [Fundação de Apoio Universitário] e federal, isso é terrível, ela faz a mesma coisa que eu e ganha metade que eu ganho. 0 ganhar, o poder aquisitivo das pessoas é muito importante. A pessoa tem que ganhar para ter, ou para conseguir para ser mais feliz. Isso é grande, o poder aquisitivo, o poder de compra, de lazer, aonde eu vou ela vai. É horrível (P2).

O funcionário público seria mais acomodado, e o celetista não, porque tem que manter o emprego, mas, muitas vezes quando tu tens cursos, tens coisas, é completamente ao contrário. O público, pode ver, as pessoas hoje que estão fazendo o mestrado, não só pelo incentivo financeiro, são os federais (P5).

O comprometimento, a gente tem tanto da FAU quanto federal, e 0 descomprometimento também. Acho que vai muito da pessoa, naquilo que tu acredita, que tu quer da vida (P7).

As relações de trabalho igualmente são destacadas como aspecto vulnerável entre as equipes 
comprometendo o trabalho na Enfermagem e a visão global sobre a continuidade do trabalho assistencial.

[...] a questão de relacionamentos também. Acho que o relacionamento é muito bom interno, na sua unidade de equipe, mas as pessoas não ultrapassam aquele limite. Então, muitas vezes, não tem relacionamento com a noite; só com a tarde (P5).

A Enfermagem é uma sequência. Só que ninguém vê isso. Tipo, se ficou alguma coisa de um turno, que pode dar sequência no outro, a pessoa não vê aquilo dali como sequência. Já chega e já vai chamando a colega de incompetente, e às vezes não é isso. É não dar sequência (P6).

\section{Visão dos enfermeiros acerca das potencialidades no processo de trabalho da Enfermagem}

Manter a qualificação profissional foi aspecto identificado neste estudo como fortaleza e potencialidade para a Enfermagem empoderar-se e fundamentar a prática profissional.

A nossa equipe enquanto técnica e auxiliar é mais capacitada que os enfermeiros, até porque não nos capacitamos muito. Porque houve um tempo que queríamos trabalhar, queríamos prática. Então não tinha uma especialização, e se tinha era em Porto Alegre [...]. A questão da atualização tem que ser constante. Anda nesse mundo globalizado, temos várias ferramentas, a internet [...], realmente de trabalhar as potencialidades ou aplicar nosso conhecimento em prol da coletividade (P1).

Em relação às equipes que trabalham há muitos anos juntos, principalmente a nossa qualificação [...] na Enfermagem é presente. Não trabalhamos com pessoal de nível médio. A maioria tem ensino superior, e isso muda, sim. Modifica atitude, posicionamento, postura, maior possibilidade de crescer como profissional (P2).

Outra fortaleza importante percebida pelos enfermeiros no processo de trabalho é a questão de menor número de leitos atendidos pela Enfermagem, o que propicia a qualificação no atendimento assistencial.

[...] estive há pouco em um hospital de Porto Alegre e também de Santa Maria (RS), e vejo que nós temos um contingente maior, em relação a números de técnicos de Enfermagem, enfermeiros por pacientes. Para vocês terem uma ideia lá, é um enfermeiro à noite para cada 90 leitos. Aqui, nós ficamos com um enfermeiro para cada 25. Então, nós temos, sim, um alargamento de escala que faz com que 0 enfermeiro veja por turno cada paciente, examine o paciente, vá até 0 leito, converse com a família, que preste assistência a cabeceira (P2).

Em termos de técnico de Enfermagem, temos um número de cinco leitos para cada técnico de Enfermagem, nas áreas clínicas. Nas UTIs, temos um e meio para cada leito. Então, é presente, é verdadeiro (P2).

Visão dos enfermeiros acerca das estratégias para mudança no processo de trabalho da

\section{Enfermagem}

Uma estratégia reconhecida nas falas dos participantes foi a aproximação da faculdade de Enfermagem à gerência de Enfermagem do Hospital-escola. Tal fato proporcionou 0 alinhamento e 0 desenvolvimento das ações de Enfermagem por meio da inclusão de docentes nas reuniões da 
gerência do hospital com discussão focada na prática.

Eu acho que existe um encontro nesse momento, da faculdade de Enfermagem junto com nosso serviço, e acho que tanto o ensino precisa melhorar quanto a assistência. Então, com certeza, nessa gerência compartilhada, e essa assistência que pretendemos seja compartilhada, a gente vai gerar uma qualificação para 0 ensino e, consequentemente, para a assistência [...]. Nós vamos tentar montar alguns projetos. Já pedimos ajuda aos professores para que possamos ter os alunos conosco em alguns projetos de extensão (P2).

[...] Eu acho que tu tem que criar uma união de conhecimento tanto da prática quanto da academia, para dizer: isso é viável, isso é possível, isso é feito, isso existe (P4).

Vislumbra-se que a discussão coletiva e a reflexão permanente da prática de assistência possibilitam qualificar a organização do trabalho da Enfermagem.

Eu acho bastante interessante porque já faz o diagnóstico, né. Importante porque faz com que os enfermeiros pensem no seu processo de trabalho, 0 que 0 enfermeiro está pensando de fato [...]. Entender sobre o objeto de trabalho, que tem outras ferramentas necessárias para entendermos essa questão que envolve todo 0 processo de trabalho. Então, acho que, no geral, com tudo isso que falou, dá pouco mais de entendimento de como o enfermeiro do Hospital-escola organiza, na verdade, seu trabalho (P1).

Nesse grupo focal, por exemplo, para nós que somos supervisores, queremos algumas pequenas mudanças, [...] e que num futuro próximo teremos grandes mudanças, que o trabalho pode nos ajudar a isso (P4).

Nesse sentido, alinhado a esse aspecto de discussão permanente, é estratégico a abordagem de reflexões acerca das relações interprofissionais para melhorar a comunicação e os ruídos no processo de trabalho.

[...] na realidade, nosso trabalho todo é pautado, baseado no que fazemos com nossa equipe, com nossas relações de trabalho, que nós vamos ter uma boa qualidade de vida se tivermos boa qualidade de trabalho, e são essas mudanças que queremos que ocorra (P4).

Acho que temos grandes potencialidades, e estamos abertos [...] a começar a fazer o diagnóstico das situações, do dia a dia de nosso trabalho; buscar formas de como melhorar; e melhorar nossas relações, as interações (P1).

Eu acharia muito bom se tivessem reuniões periódicas com os enfermeiros, assim uma vez por mês, até para integrar, ter essa comunicação. Acho que facilitaria [...]. Ainda estamos empenhados nesse modelo de assistência fragmentada, biomédico. Com o tempo, isso vai acabar trazendo mudanças (P7).

Implementar a SAE é fundamental dentro do âmbito hospitalar e fortalece o trabalho da Enfermagem e a qualificação da assistência.

[...] precisa ter prescrição, sim. Precisa ter o aprazamento, sim, para o enfermeiro [...] poder dar assistência adequada, se ele está comendo ou não, o que está comendo. Então, precisa ter. Quanto mais [...] for usado registro, mais vai ter 0 enfermeiro chegando perto do paciente (P2). 
Se tivessem as normas e rotinas, talvez, por isso eu digo, se tivesse a sistematização, diminuiria o trabalho da $\mathrm{CCIH}$ (Comissão de Controle de Infecção Hospitalar) de ir todos os turnos, Falo de manhã, falo de tarde e falo de noite (P5).

\section{DISCUSSÃO}

A liderança pode ser caracterizada pela liberdade de que um indivíduo tem para tomar decisões e influenciar o coletivo, tomando a responsabilidade para si em decorrência de suas atribuições e funções dentro da equipe. Dessa forma, faz-se necessária uma reflexão teórica por parte do enfermeiro a respeito de como conduzir a liderança dialógica nos serviços de saúde. Isso porque as relações de hierarquização e verticalidade de poderes podem estar presentes no cotidiano profissional levando a barreiras conflituosas ou não, mas que interferem no desenvolvimento da atividade profissional. Assim, a liderança dialógica pode contribuir para mudanças positivas no que se diz respeito à equipe de Enfermagem(11).

A liderança dialógica atua como suporte para a potencialização das relações interpessoais, no qual o enfermeiro como líder da equipe tem a consciência de seu papel em influenciar e ser influenciado por seus colaboradores(12). Percebe-se que a equipe de Enfermagem espera do enfermeiro uma atitude, e não somente focar no paciente e no cuidado, mas também nos demais indivíduos da equipe para romper com o modelo de liderança opressor.

As divergências de ideias são os principais motivos para a existência de conflitos na área da saúde. Para isso, espera-se que o líder da equipe, o enfermeiro, tenha uma conduta coerente diante dessas situações desagradáveis. Isso exige um posicionamento enquanto gerente de Enfermagem. Entretanto, o enfermeiro necessita possuir autonomia, respeito da sua equipe e, principalmente, habilidades no processo de negociação, utilizando-se da estratégia mais adequada para solucionar ou reduzir os conflitos que acontecem no ambiente de trabalho(13).

A Teoria dos Vínculos Profissionais (TVP) consiste em uma proposta de qualificação das relações humanas no trabalho da Enfermagem por meio do fortalecimento do trabalho em equipe. Através da TVP criam-se e intensificam-se as relações interpessoais e a dimensão da subjetividade presentes no local de trabalho. Dessa maneira, pode-se trabalhar com os enfermeiros por meio de reuniões e avaliar as ações, além de criar e formatar e vínculos entre as equipes, com a finalidade de aproximar esses profissionais. Tal procedimento contribui para a potencialização da qualidade do trabalho e, consequentemente, a criação de um ambiente saudável(5).

Contudo, a comunicação inadequada pode ser uma barreira não somente para a construção de vínculos, mas para uma má qualidade na assistência prestada quando realizada durante a passagem de plantão, por exemplo. A comunicação é uma ferramenta de trabalho que os profissionais de 
Enfermagem podem utilizar desde a formação, tanto pelos docentes, orientando e estimulando através de metodologias ativas, seja durante os estágios em que os preceptores direcionam os alunos a exercerem a comunicação com o paciente, o familiar, a equipe de Enfermagem e outras equipes dentro da organização de saúde(14).

Logo, a comunicação é a principal ferramenta que o enfermeiro tem para gerir seu processo de trabalho. A falha, ou a falta, de comunicação interfere no relacionamento entre os profissionais e no serviço prestado. Ou seja, o processo de comunicação e o relacionamento interpessoal efetivo devem ser norteados por sentimentos, efetividades, respeito, sinceridade, honestidade, confiança até alcançar a efetividade. Assim serão benéficos por meio do diálogo validado pelo preceptor, promovendo interação e proporcionando fluidez no trabalho em equipe e, consequentemente, na assistência de Enfermagem. ${ }^{115)}$

No entanto, quando os participantes mencionam a falta ou a ausência de normas técnicas, isso pode acontecer pelo fato de haver desinteresse dos indivíduos frente ao caso. Isso porque as rotinas e normas só irão ser efetivas quando os enfermeiros começarem a buscá-las e colocá-las em prática em seu dia a dia. Ou seja, quando as inserirem em suas atividades cotidianas, o que pode contribuir e solicitar uma mudança nesse contexto.

Nas falas apresentadas, é possível identificar a resistência dos enfermeiros a mudanças no processo de trabalho. Dessa forma, entende-se a Sistematização da Assistência de Enfermagem (SAE) como uma ferramenta metodológica de trabalho do enfermeiro que possibilita organizar suas ações e auxiliar o profissional no desenvolvimento de uma assistência de qualidade, desde que fundamentada por modelos ou Teorias de Enfermagem.

A SAE permite reorganizar e sistematizar as ações e práticas de saúde. Além disso, a efetivação da SAE só será possível de ser implementada quando a instituição e a equipe 0 considerarem como ferramenta para qualificar o processo de trabalho. Ele irá depender também do referencial de gestão e das estratégias utilizadas, para assim permitir a reorganização do cuidado(16).

Nota-se que os enfermeiros possuem incentivos da própria instituição para a qualificação profissional, principalmente os estatutários, que, além de se capacitarem, ganham um incentivo financeiro de acordo com seu regime de trabalho. Existe, porém, uma discrepância entre os regimes de estatutários e celetistas, nos quais os estatutários estão mais satisfeitos com salário e promoções. A explicação para tal fato deve-se à existência de um plano de carreira, o qual é único e para os estatutários(17).

O distanciamento entre a faculdade de Enfermagem e o processo de trabalho da assistência hospitalar foi apresentado nas falas, embora a Universidade Federal de Pelotas desenvolva ações 
junto ao Hospital de Ensino durante o ano letivo. No entanto, é notória a insatisfação dos enfermeiros quanto ao distanciamento entre os acadêmicos e residentes com as equipes de Enfermagem. Eles não constroem vínculos; não há a situação de troca de informações a respeito dos pacientes ou do cuidado prestado. 0 que é incoerente com o objetivo de um Hospital de Ensino, pela indissociabilidade entre 0 ensino, a extensão e a pesquisa. Ou seja, a universidade necessita estar ligada e articulada diretamente com a assistência prestada no hospital.

O aprendizado inerente ao campo da vida cotidiana da instituição é destacado pelos participantes. Enquanto isso, incentiva mudanças nas estratégias educativas de modo a focar a prática como fonte de conhecimento e a equipe de Enfermagem atuar efetivamente no processo educativo. É relevante, portanto, considerar-se nessa instituição a educação permanente enquanto estratégia para a qualificação dos trabalhadores(18).

Já o quantitativo de profissionais para a realização da assistência apresenta-se como potencialidade, por responder diretamente aos pacientes, o que permite um contato maior com a equipe de Enfermagem. Na maioria das unidades estudadas, o quantitativo de profissionais está adequado em relação ao quantitativo de pacientes segundo os parâmetros do Conselho Federal de Enfermagem (Cofen)(19).

Dessa forma, a integralidade do cuidado deve ser vista com um olhar mais amplo e humanizado, considerando o ser humano como um todo (espiritual, emocional, físico, familiar) e contemplando as ações de Enfermagem para todo esse contexto. Como os profissionais assumem 0 compromisso de realizar um cuidado integral, remetem a um novo modelo de atenção e de ensino, através de uma abordagem em saúde que valoriza a dimensão subjetiva que reconheça o singular sem desprezar o coletivo. Assim, esse cuidado é ampliado para além daquele de Enfermagem, pois desempenha papel relevante na determinação da satisfação geral da experiência de hospitalização do paciente e dos múltiplos cuidados oferecidos(20).

É evidente nas falas dos participantes a vontade de prestar um cuidado integral e de qualidade. A satisfação profissional e a valorização do trabalho também são preponderantes para seu desempenho profissional. Ampliar a visão do processo de trabalho possibilita compreender o que se passa à sua volta, o que inclui as características interdisciplinares, pois estas contribuem para o processo de humanização. Assim, possibilita-se o respeito à individualidade e às diferenças profissionais de outras disciplinas que unem esforços para a construção de um modelo de atendimento centrado no indivíduo como um ser integral(21).

Ademais, algumas estratégias para mudanças foram discutidas no grupo focal. Entre elas, a aproximação da faculdade de Enfermagem com a chefia de Enfermagem do Hospital-escola. São 
evidentes a necessidade e a vontade de realizar a ligação entre a assistência e 0 ensino, em que a faculdade de Enfermagem traz como bagagem a teoria, o conhecimento, a pesquisa e a assistência com a experiência das ações da prática hospitalar.

Uma sugestão é a aproximação dos alunos com os projetos de extensão, o que possibilitaria a troca de experiências e mais qualidade na assistência ao paciente. A extensão universitária caracterizase pela indissociabilidade da pesquisa com o ensino, devendo ser discutida, planejada de maneira dinâmica e executada por meio de ações permanentes. Ademais, pode ser um caminho de formação que viabiliza transformações sociais ao afastar as atividades extensionistas das concepções assistências mercantilistas(22).

Os participantes reconhecem a comunicação no trabalho da equipe de Enfermagem como algo importante, devendo ser incentivada por mais vezes, como em reuniões. No entanto, esse processo deve ser de forma coerente e clara, a fim de integrar a equipe de Enfermagem e conseguir, dessa forma, a busca de objetivos e metas comuns da equipe. Além disso, convém observar 0 comportamento de quem se comunica, não somente na fala, devendo-se importar com a qualidade e 0 contexto em que o processo de comunicação está envolvido. Isso porque quem cuida e quem recebe 0 cuidado necessita perceber, identificar e entender o que mais está envolvido na comunicação além da fala(15).

Por outro lado, as relações interpessoais são primordiais para a manutenção de um local de trabalho saudável, com a realização de ações de cuidado de forma qualificada. Os resultados implicam a necessidade de luta por condições que possibilitem maior qualidade de vida no trabalho dos enfermeiros e venham qualificar a assistência de Enfermagem para o cuidado de indivíduos, família e comunidade.

Por fim, os participantes inferem que a SAE é uma maneira de fortalecer o trabalho da Enfermagem e de qualificar a assistência, apresentando-se como um guia que orienta as ações de Enfermagem, a fim de atender às necessidades dos pacientes. Ainda qualifica a assistência de Enfermagem por constituir uma estratégia de organização do processo de trabalho. Além disso, proporciona autonomia para a profissão, por representar uma metodologia de assistência reconhecida pelos enfermeiros, bem como permitir uma aproximação junto ao paciente. Assim, cabe a importância da instituição em apoiar e valorizar essa proposta para facilitar o trabalho do enfermeiro e a adesão do paciente ao processo(23,24).

\section{Limitações do estudo}

A principal limitação deste estudo foi a dificuldade de identificar um horário disponível para 
agrupar a maioria dos sujeitos, devido ao fato de os enfermeiros terem mais de um vínculo empregatício. Contudo, o grupo heterogêneo foi fator positivo para a discussão do processo de trabalho, pois os enfermeiros têm suas próprias concepções e visão de mundo a partir de suas experiências.

\section{Contribuições para a área da Enfermagem, saúde ou política pública}

Destarte, esta pesquisa ratifica a necessidade de construir momentos para a reunião dos profissionais em espaços de discussão e troca de informações, de maneira que os participantes reflitam sobre seu processo de trabalho. Desse modo, os momentos de encontro permitem que não fiquem apenas recebendo ordens ou orientações, mas que colaborarem com a instituição por meio de informações que esclareçam suas angústias, seus desejos e seus pensamentos, a fim de aprimorar o desempenho profissional.

\section{CONSIDERAÇÕES FINAIS}

Foi possível analisar o processo de trabalho dos enfermeiros de um Hospital-escola com ênfase no contexto e no ambiente de trabalho. Utilizou-se de grupos focais, o que estimulou a interação entre os enfermeiros, a fim de intensificar as relações e promover a reflexão sobre o trabalho.

Os enfermeiros discutiram e construíram estratégias para possíveis mudanças das fragilidades. Um aspecto de destaque encontra-se na importância de implementar a SAE para facilitar 0 entendimento e o reconhecimento do trabalho da equipe de Enfermagem. Outros pontos foram mencionados, porém com menos ênfase, como a realização de projetos de extensão e as vivências dentro do hospital, o investimento na qualidade de vida do trabalho e no relacionamento com a instituição e, principalmente, a integração entre o ensino e a pesquisa, através da gerência compartilhada entre hospital de ensino e faculdade de Enfermagem.

Um tema relevante que emergiu dos dados é o distanciamento dos estudantes com a prática hospitalar, apontando para que haja mais interação entre ambos. Enfatiza-se que as reuniões entre docentes e chefia de Enfermagem são uma maneira de construir estratégias para o trabalho em conjunto, com intuito de proporcionar conhecimento técnico e científico tanto para os enfermeiros quanto para os acadêmicos, o que possibilita uma assistência de maior qualidade para os pacientes.

\section{Fomento}

Pesquisa financiada sob o processo no 479.662/2010-0 do Conselho Nacional de Desenvolvimento Científico e Tecnológico (CNPq), através do Edital Universal MCT/CNPq no 14/2010, 
com vigência de 24 meses.

\section{REFERÊNCIAS}

1. Sanna MC. Os processos de trabalho em Enfermagem. Rev Bras Enferm [Internet]. 2007 [citado 2019 Jul 02];60(2):221-224. Disponível em: http://www.scielo.br/pdf/reben/v60n2/a17v60n2.pdf.

2. Pires DEP. A Enfermagem enquanto disciplina, profissão e trabalho. Rev Bras Enferm [Internet]. 2009 [citado 2019 Jun 19];62(5):739-44. Disponível em: http://www.scielo.br/pdf/reben/v62n5/15.pdf.

3. Vandresen L, Pires DEP, Lorenzetti J, Andrade SR. Classification of patients and nursing staff's sizing: contributions of a management technology. Rev Gaúch Enferm [Internet]. 2018 [citado 2019 Jun 8];39: 1-8. Disponível em: http://www.scielo.br/pdf/rgenf/v39/en_1983-1447-rgenf-39e2017-0107.pdf

4. Thofehrn MB, Montesinos MJL, Jacondino MB, Fernandes HN, Gallo CMC, Figueira AB. Work processes of nurses in health production in a University Hospital in Murcia/Spain. Cienc Cuid Saúde [Internet]. 2015 [citado 2019 Jun 11];14(1):924-32. Disponível em: http://www.periodicos.uem.br/ojs/index.php/CiencCuidSaude/article/view/22094/14352

5. Thofehrn MB; Carvalho LA; Bettin AC; Fernandes HN. Equipe de Enfermagem com vínculos profissionais saudáveis. In: Thofehrn MB (Org). Enfermagem: manual de gerenciamento. Porto Alegre: Moriá; 2016. p. 143-164.

6. Thofehrn MB, Amestoy SC, Porto AR, Arrieiral CO, Dal Pai D. A dimensão da subjetividade no processo de trabalho da Enfermagem. Rev Enferm Saúde. Pelotas (RS) [Internet]. 2011 [citado 2019 Jul 04];jan-mar;1(1):190-198. Disponível em: file:///C:/Users/not/Downloads/3423-7551-1PB\%20(1).pdf.

7. Thofehrn M, Montesinos MJ, Amestoy S, Porto A, Bettin A, Fernandes H et al. Trabajo en equipo: visión de los enfermeros de un hospital de Murcia/España. Enfermería global [Internet]. 2014 [citado 2019 Jun 12];13(4):223-52. Disponível em: https://revistas.um.es/eglobal/article/view/eglobal.13.4.190421/165721

8. Kinalski DDF, De Paula CC, Padoin SMM, Neves ET, Kleinubing RE, Cortes LF. Focus group on qualitative research: experience report. Rev Bras Enferm [Internet]. 2017 [citado 2019 Jun 12];70(2): 424-429. Disponível em: http://www.scielo.br/pdf/reben/v70n2/0034-7167-reben-7002-0424.pdf. 
9. Minayo MC. O desafio do conhecimento: pesquisa qualitativa em saúde. 14. ed. São Paulo: Hucitec; 2014.

10. Brasil. Ministério da Saúde. Conselho Nacional de Saúde. Resolução n. 466, de 12 de dezembro de 2012. Diretrizes e normas regulamentadoras de pesquisa envolvendo seres humanos [Internet]. Diário Oficial da União 13 jun 2013 [citado 2019 Jul 04]. Disponível em: http://conselho.saude.gov.br/ultimas_noticias/2013/06_jun_14_publicada_resolucao.html.

11. Amestoy SC, Lopes RF, Santos BP, Dornelles C, Fuculo Junior PRB, Santos EA. Exercício da liderança do enfermeiro em um serviço de urgência e emergência. Revista Eletrônica Gestão \& Saúde [Internet]. 2016 [citado 2019 Jun 21];(71):38-51. Disponível em: http://periodicos.unb.br/index.php/rgs/article/view/3372/3056.

12. Amestoy SC, Oliveira AFL, Thofehrn MB, Trindade LL, Santos LP, Bao ACP. Contributions of Paulo Freire to understanding the dialogic leadership exercise of nurses in the hospital setting. Rev Gaúch Enferm [Internet]. 2017[citado 2019 Jun 11];38(1). Disponível em: http://www.scielo.br/pdf/rgenf/v38n1/en_0102-6933-rgenf-1983-144720170164764.pdf.

13. Lorenzini E, Mientkewic G, Deckmann L, Bazzo K, Silva E. Conflitos na equipe de Enfermagem: [Internet]. 1 [citado 2019 Jul 04];6(2):1764-773. Disponível em: http://periodicos.unb.br/index.php/rgs/article/view/3011.

14. Leal LA, Soares MI, Silva BR, Bernardes A, Camelo SHH. Clinical and management skills for hospital nurses: perspective of nursing university students. Rev Bras Enferm [Internet]. 2018 [citado 2019 Jun 12];71(Suppl 4):1514-21. Disponível em: http://periodicos.unb.br/index.php/rgs/article/view/3011

15. Broca PV, Ferreira MA. Nursing team communication in a medical ward. Rev Bras Enferm [Internet]. 2018 [citado 2019 Jun 12];71(3):951-8. Disponível em: http://www.scielo.br/pdf/reben/v71n3/0034-7167-reben-71-03-0951.pdf

16. Soares MI, Resck ZMR, Terra FS, Camelo SHH. Systematization of nursing care: challenges and features to nurses in the care management. Esc Anna Nery [Internet]. 2015 [citado 2019 Abr 17];19(1):47-53. Disponível em: http://www.scielo.br/pdf/ean/v19n1/en_1414-8145-ean-1901-0047.pdf.

17. Ribeiro DCM, Kuroba DS. Fatores que levam os profissionais de Enfermagem ao absenteísmo no Brasil. Cad Saúde Des [internet]. 2016 [citado 2019 Jun 12];9(5). Disponível em: https://www.uninter.com/cadernosuninter/index.php/saude-edesenvolvimento/article/view/441/374. 
18. Sade PMC, Peres AM. Desenvolvimento de competências gerenciais do enfermeiro: diretriz para serviço de educação permanente. Rev Esc Enferm USP [internet]. 2015 [citado 2019 Jun 13]; 49(6):991-998. Disponível em: http://www.scielo.br/pdf/reeusp/v49n6/pt_0080-6234reeusp-49-06-0991.pdf

19. Fugulin FMT, Lima AFC, Castilho V, Guimarães CP, Carvalho A, Gaidzinski RR. Nursing staff in the internal medicine and surgical units of teaching hospitals: composition and cost. Rev Esc Enferm USP [Internet]. 2015 [citado 2019 Jun 13];49(Esp2):48-54. Disponível em: http://www.scielo.br/pdf/reeusp/v49nspe2/en_1980-220X-reeusp-49-spe2-0048.pdf.

20. Kasa AS, Gedamu H. Predictors of adult patient satisfaction with nursing care in public hospitals of Amhara region, Northwest Ethiopia. BMC Health Serv Res [Internet]. 2019 [citado 2019 Jul 10];19(52):2-9. Disponível em: https://bmchealthservres.biomedcentral.com/track/pdf/10.1186/s12913-019-3898-3.

21. Horst VSB, Orzechowski ST. O desafio e potencialidade da interdisciplinaridade no atendimento à saúde. Laplage em Revista (Sorocaba) [Internet]. 2019 [citado 2019 Jun 10];3(1):192-201.

Disponível

em: http://www.laplageemrevista.ufscar.br/index.php/lpg/article/view/230/476.

22. Kochhann A, Silva ME, Amorim MCS. Extensão universitária acadêmica, processual e orgânica: um projeto de formação de professores. R UFG Goiânia [Internet]. 2018 [citado 2019 Jun 15];18(22):61-89. Disponível em: https://www.revistas.ufg.br/revistaufg/article/view/51563/25917.

23. Ribeiro GC, Padoveze MC. Nursing care systematization in a basic health unit: perception of the nursing team. Rev Esc Enferm USP [Internet]. 2018 [citado 2019 Jun 15];52:e03375. Disponível em: http://www.scielo.br/pdf/reeusp/v52/1980-220X-reeusp-52-e03375.pdf.

24. Alencar IGM, Nunes VS, Alves AS, Lima SLR, Melo GKM, Santos MAF. Implementação e implantação da sistematização da assistência de Enfermagem. Rev Enferm UFPE On-line [Internet]. 2014 [citado 2019 Jun 15];12(4):1174-8. Disponível em: https://periodicos.ufpe.br/revistas/revistaenfermagem/article/download/231030/28716. 